\title{
Urban transport systems in Latin America and the Caribbean: lessons and challenges
}

\author{
Patricia Yañez-Pagans ${ }^{1 *} \mathbb{B}$, Daniel Martinez ${ }^{2}$, Oscar A. Mitnik² ${ }^{2}$ Lynn Scholl² and Antonia Vazquez ${ }^{3,4}$
}

\author{
*Correspondence: \\ patriciaya@iadb.org \\ ${ }^{1}$ IDB Invest, Washington \\ D.C., USA \\ Full list of author information \\ is available at the end of the \\ article
}

\begin{abstract}
This paper discusses the transportation challenges that urban areas in Latin America and the Caribbean face and reviews the causal evidence on the impact brought by different urban transport system interventions implemented around the world. The objective is to highlight the main lessons learned and identify knowledge gaps to guide the design and evaluation of future transport investments. The review highlights that causal studies have been concentrated in certain areas and that an important number have been carried out in developed countries. Empirical challenges due to the non-random placement of these interventions and their possible effects over the entire transport network might explain the reduced amount of causal evaluations. A large part of the literature has focused on the impact of transport systems on housing values, finding overall increases in prices and rents, but with results highly dependent on the quality and perceived permanency of the system. Few studies have explored socioeconomic effects, and those available have emphasized employment access. There are almost no studies exploring displacement effects, which should be further examined to better understand the social inclusion role of transport systems. New avenues of research are emerging that exploit non-traditional sources of data, such as big data and satellite information. Moreover, studies looking at ways to improve the operational efficiency of systems and those seeking to promote behavioral changes in transport users offer great potential to generate learning that is useful for the public and private actors involved.
\end{abstract}

Keywords: Urban transport systems, Latin America and the Caribbean, Impact evaluation

JEL Classification: $018, R 15, R 42$

\section{Introduction}

Rapid population growth, urbanization, and widespread use of motor vehicles have generated large mobility challenges in urban areas of Latin America and the Caribbean (LAC), including high rates of congestion, traffic accidents, and pollution (CAF 2010). Although a significant share (68\%) of passenger travel in LAC cities is on public transit or shared systems (Estupiñan et al. 2018), the supply of high-quality public transport has not kept pace with the growth in transport demand (IDB 2013). In combination with increased incomes and, in some cases, policies directed at encouraging purchases of new cars, this has generated a surge in motorization rates (De la Torre et al. 2009), leading to increased pressure on urban transport infrastructure.

(c) The Author(s) 2019. This article is distributed under the terms of the Creative Commons Attribution 4.0 International License (http://creativecommons.org/licenses/by/4.0/), which permits unrestricted use, distribution, and reproduction in any medium provided you give appropriate credit to the original author(s) and the source, provide a link to the Creative Commons license, and indicate if changes were made. 
Unplanned urban growth and income inequality have also prompted the poor to settle in informal housing on the periphery of large cities, often in areas difficult to serve with traditional or formal public transit systems (Cervero 2000). As a result, the urban poor either forgo trips or endure long and costly travel times to get to their jobs or carry out other tasks, a circumstance that aggravates social inequalities (Ardila-Gomez 2012). In addition, women, particularly those from lower-income segments, have less accessibility and mobility due to personal safety concerns and high rates of harassment in crowded transit systems (Osmond and Woodcock 2015; Simicevic et al. 2016). Affordability of transportation is another challenge, as travel expenditures consume $30 \%$ or more of labor income of the poor in the region, adding to already high travel time costs (Kaltheier 2002; Vasconcellos 2001).

In response to all of these issues, the LAC region has seen a renewed focus on urban transport interventions and an important increase in investments directed toward improving transport systems over the past two decades (Infralatam 2018). Given financing gaps and the need to improve operational and managerial efficiency in the sector, governments are also increasingly engaging with the private sector, and there are several examples of successful public-private partnerships (PPPs) in transport in the region (Vassallo Magro 2015). Regarding the types of investments, bus rapid transit (BRT) systems have become an increasingly popular approach to cost-effectively improve urban mobility ${ }^{1}$ (Rodríguez and Mojica 2009). As these systems have matured, and in many cases have reached ridership saturation levels (O'Callaghan 2016), larger cities in higher-income LAC countries have begun investing in metro systems and light rail, while others have invested in cable cars. For cities with well-established systems, more sophisticated interventions have emerged that aim to improve the operational efficiency and accessibility to more vulnerable populations. These efforts include policies such as integrated tariffs or transport subsidies to maximize demand and/or increase affordability for lower-income groups.

Given that resources are scarce, a first-order question for policymakers relates to the impact that these infrastructure investments are having. The expectation is that improving accessibility and mobility should promote greater access to employment, services, and other opportunities, as well as improved road safety and citizen security. But benefits might not be distributed equally across all groups of the population, or might not be realized at all (Scholl et al. 2018). These types of investments are also often associated with changes in land use and a rise in property values, which can have important implications for housing affordability and potential displacement of disadvantaged individuals. Other important questions, usually on the operation side of the system, relate to the impact of "soft" components that seek to increase demand (particularly off-peak demand) and access to the system. For this, behavioral theories are increasingly being used to understand passenger responses.

This paper presents a review of causal studies that provide evidence on the effectiveness of different urban transport interventions. Although the focus is on LAC, given that

\footnotetext{
${ }^{1}$ This trend follows the initial success of BRT systems in Curitiba, Brazil and Bogota, Colombia. Curitiba, Brazil was the first city to develop a BRT system in 1977. Based on Curitiba's model, Bogota, Colombia built its first BRT line in 2000, incorporating technological innovations that led to it achieving the highest capacities and speeds of any BRT system in the world.
} 
there are still few causal studies for the region, this work attempts to include studies conducted worldwide that are relevant for this analysis and that exploit experimental or quasi-experimental methods. The work at hand has two objectives. The first is to summarize the existing knowledge to inform policymaking in the region. The second is to identify the main knowledge gaps, highlighting potential avenues of future research. Urban transport interventions cover a wide range of alternatives; the focus here is only on passenger transportation systems such as subways, light rail, BRT, cable cars, and transport network companies (TNC). Driving restriction interventions are also discussed, given their potential to affect the demand for passenger transport systems. Other interventions, such as road and highway improvements and interventions related to intelligent traffic management systems, although important, fall outside the scope of this review.

A prior literature review related to this topic was prepared by Boarnet (2007), which carefully discussed the methodological issues related to urban transport causal evaluation. Given the predominance of cost-benefit analysis in the transport sector, the author highlights that impact evaluations should not replace welfare studies, but that are key to provide a more direct link with poverty alleviation effects. According to Boarnet (2007), the link between transportation access and labor market success is the most relevant, but little research has been identified in developing countries. The present paper complements and updates this previous report. Although the present work provides a general discussion on the main methodological challenges in this area, the focus is on describing the findings of a wider set of urban transport interventions, thus providing a more comprehensive view of the causal studies available and the main knowledge gaps.

The limited number of causal studies in urban transport is explained by the empirical complexities that arise when trying to distinguish between effects that can be attributed to transport investments versus those that result from the non-random placement of these investments and that might benefit populations that were already better connected, had higher employment rates, or had higher incomes, among other demand considerations. There is also an important aspect of firm and household dynamic location decisions, given that any benefits identified might not necessarily reflect the welfare gains obtained by the original population living in project-served areas, but rather might reflect the fact that new populations with distinct characteristics (i.e., compositional changes) are moving in (Cortes et al. 2017). For certain interventions that have the potential to change the entire transport network, identifying pure comparison groups (i.e., populations or areas not affected by the intervention) might be a challenge as well.

The review of the evidence shows that the literature has focused on the impact of transport systems on housing values, driven by the availability of information and the speed of price responses to changes in urban infrastructure. Those studies, in general, find increases in prices and rents, but results seem to be highly dependent on the context and on how permanent the real estate market participants perceive the transport investments to be. For example, the evidence on subways and light rail is quite conclusive, while the evidence for BRT systems is less conclusive, as these systems can be changed or reallocated over time. On the other hand, there are few studies exploring socioeconomic and displacement effects. The findings in this area seem quite heterogeneous, probably due to the complexities underlying labor market access and poverty. The lack of studies 
that examine socioeconomic outcomes could be due to data limitations, including the difficulty of following households over time and the time that these impacts might take to appear. New avenues of research are starting to emerge that exploit non-traditional sources of data, such as administrative data and big data generated by satellite images, mobile phone calls and apps, among others. Moreover, given the wide variation in the quality and reliability of transport services, much research is still needed on the impact of service quality on aspects such as ridership, employment, and pollution, among other things.

The next section of this paper presents an overview of the situation of urban mobility in the LAC region, highlighting progress and challenges. Section 3 describes the main theories guiding the modeling of the impact expected from urban transport systems. Section 4 reviews the evidence available on diverse types of urban transport system interventions, and Sect. 5 discusses the main findings and recommendations emerging from this work.

\section{Urban transport in Latin America: progress and remaining challenges}

Latin America and the Caribbean have experienced explosive urbanization in the last 40 years, with the share of its urban population increasing from $50 \%$ of the population in 1970 to $80 \%$ by 2013 (United Nations 2011). In addition, robust income growth and a sharp expansion of the middle class have spurred a rapid increase in automobile and motorcycle ownership. With an average of approximately 90 vehicles per 1000 population, the motorization rate in LAC exceeds those of Africa, Asia, and the Middle East (De la Torre et al. 2009). However, there is heterogeneity across countries. For example, between 1990 and 2010, per capita car ownership more than doubled in Mexico from about 75 to 175 cars per 1000 population, and nearly tripled in Brazil from 45 to 125 cars per 1000 population (Fay et al. 2017). Moreover, growth in motorcycle ownership has surpassed that of autos in many LAC cities, where motorcycles make up as much as $49 \%$ of the vehicle fleet (UN-Habitat 2012).

While investments in infrastructure for passenger transport have increased recently, the supply of high-quality public transport and road infrastructure has not kept pace with the growth in transport demand. Weak institutions and government oversight have also exacerbated the inefficiency and informality of urban transport systems (Pazos 2016), contributing to unsafe conditions and increased levels of congestion and pollution, particularly in lower-to-middle income LAC cities (IDB 2013). In 2010, the LAC region reported an average rate of 25.3 fatalities per 100,000 population associated with car accidents, compared to 16.1 fatalities per 100,000 population in the USA and Canada (IDB 2013). In addition, the average one-way commute time reached up to $2 \mathrm{~h}$ in some cities, imposing considerable time and monetary costs on both freight and passenger transport (UN-Habitat 2012). According to a report by the Clean Air Institute, air pollution levels in many LAC cities exceed World Health Organization (WHO) guidelines for major pollutants, posing significant adverse costs to human health, life expectancy, and productivity (Green and Sánchez 2013).

On average, $68 \%$ of all trips in LAC are via collective or public transport (Estupiñan et al. 2018). The bus sector dominates these trips. Initially publicly owned, the bus sector in the region underwent widespread deregulation and privatization in the early 1980s 
and 1990s, spurring an oversupply of mini-bus operators that often maintain overlapping routes and compete fiercely for passengers leading to chaotic, unsafe, and congested traffic conditions. Public transport users spend between 50 and 100\% more on travel time than automobile and motorcycle users, and their safety and comfort levels are lower (Vasconcellos and Mendoça 2016). Given low car ownership rates for the poorest segments of the population, the affordability and efficiency of public bus services are also particularly important. In most LAC cities, the monthly cost of fares is over the desirable $6 \%$ of the minimum wage. As an example, in metropolitan areas in Brazil the monthly expenditure on public transportation represents $25 \%$ of the minimum wage.

Over the past two decades, governments across the LAC region have begun investing in modern urban transport systems, with the bulk of the financing taking place between 2002 and 2013. As a result of these investments, the region has seen a proliferation of BRT. Today, such systems operate in 54 cities in LAC and in 167 cities globally (WRI Brazil Ross Center for Sustainable Cities 2018). As these systems have matured, and in many cases have reached ridership saturation levels, larger cities in higher-income LAC countries have begun investing in metro systems and light rail. In 2014, 157 cities around the world had an operational metro system. There are 54 networks in Asia, 46 in Europe, and 18 in LAC, where Mexico City is the busiest network (UITP 2015). Other cities, based on their geographic characteristics and given the advantages in terms of construction costs and lower displacement of people, have implemented aerial cable cars systems. The first cable car designed as a transport system in LAC opened in Medellín, Colombia, in 2004. Since then, Caracas (Venezuela), Cali (Colombia), Mexico City (Mexico), Rio de Janeiro (Brazil), and La Paz (Bolivia) have built similar systems. Today the system in La Paz, Mi Teleférico, is considered the longest system in the world.

\section{Urban transport modeling}

The following section summarizes different theoretical perspectives that have been presented to understand transport demand and that serve to understand the potential causal effects of urban transport interventions.

\subsection{Transport use forecasting}

The mobility of people in urban areas is a complex phenomenon due to the substantial number of factors that can influence the decision-making process, thus multiple theories have been developed to guide urban transportation planning. In the classic model, individuals take sequential decisions in what is known as the four-step model (Manheim 1979; Florian et al. 1988). The first step, trip generation, predicts the number of trips originated in or destined for a traffic analysis zone as a function of land use, household demographics, and other socioeconomic factors. ${ }^{2}$ A key idea is that the intensity of activity declines with distance from the central business district. The second step is

\footnotetext{
${ }^{2}$ A traffic analysis zone is the unit of geography most commonly used in conventional transportation planning models The size of a zone varies, but usually encompasses areas that are as homogenous as possible in terms of their transport characteristics and, in general, have less than 3000 people. Therefore, the size of a traffic analysis zone could vary from very large areas in the suburbs to as small as a city block in central business districts. Usually, traffic analysis zones are constructed by relying on census block-level information. Most often the critical information includes the number of automobiles per household, household income, and employment within these zones. This information helps to further the understanding of trips that are produced and attracted within and between traffic analysis zones (Miller and ShihLung 2001).
} 
trip distribution, which matches origins with destinations, often using a gravity model, where the interaction between two locations is assumed to decline with increasing distance, time, and cost between them, but is positively associated with the amount of activity at each location (Isard 1956). The third step involves the mode choice, which computes the proportion of trips between each origin and destination that uses a particular transportation mode. Models emphasizing consumer and choice behavior concepts from economics and psychology have been used (Domencich and McFadden 1975). The fourth step is route assignment, which allocates trips between an origin and destination, by a particular mode, to a route. For this, modeling assumes drivers choose the shortest (travel time) path, subject to every other driver doing the same (Wardrop and Whitehead 1952), or else they follow the lead of a traffic manager as in a Stackelberg competition model (Stackelberg 2011).

Although the four-step model is still widely referenced in the transport literature, new types of decisions have been included in the analysis, such as the decision about the time of the trip, which has given rise to time distribution models. Another class of models, activity-based models, predict where and when specific activities (e.g., work, leisure, shopping) for individuals are conducted. The major premise behind these models is that travel demand is derived from activities that people need or wish to perform, with travel decisions forming part of the scheduling decisions. Travel is then seen as just one of the attributes of a system. Activity-based models have recently been used to predict emissions (Beckx et al. 2009) and air quality (Shiftan 2000; Hatzopoulou and Miller 2010).

Integrated transport-land-use models are intended to forecast the effect of changes in the transport network on the future location of activities, and then forecast the effect of these new locations on transport demand. As data science technologies and big data become more available, research is moving toward predicting behaviors of individual drivers, which is known as per-driver models (Fox 2018). This may be done by using driver-level data collected on cameras, social network profiles, store card purchase data, and search engine history, among other activities. This could lead to more accurate predictions, but also raises challenges about data storage and confidentiality.

\subsection{Employment, productivity, and transport}

The role of transport infrastructure on unemployment and labor informality is theorized to occur due to two main factors. The first factor is the spatial mismatch hypothesis posed by Kain (1968), who argues that the spatial segregation of low-income minorities from skill-appropriate job centers decreases the affordability of job searches and commutes, and thus increases unemployment rates among such isolated and predominately transit-dependent communities. The second factor is the reservation wage hypothesis, which states that the wage at which a person is willing to supply labor is likely to be higher with higher transport costs. Therefore, increased transport costs are more likely to limit the geographic range of job opportunities (Patacchini and Zenou 2005). The impact of transportation costs is higher on less skilled workers who have lower wages.

More recently, Franklin (2017) argues that cash-constrained job seekers decide on their optimal search intensity to equate the marginal cost of foregone consumption, due to the costs of the search, with the marginal gain of the increased probability of having a good job. In this setting, poorer individuals find it harder to search intensively because the 
marginal cost of searching is much greater for them. Franklin hypothesizes that lowering the costs of the job search (through transport subsidies) would increase the intensity and duration of job search activities through three main (possibly interrelated) channels: (1) a price effect, by changing the relative price of the search when transport subsidies are provided; (2) a wealth effect, by lowering total spending on the search, which alleviates cash constraints, lowers the marginal disutility of additional searches, and prevents the running down of savings; and (3) a time effect, by which the alleviation of cash needs can decrease the need for unemployed individuals to take temporary forms of work that impose a large time constraint that can impair their ability to search for better work.

Public transit systems in the periphery of urban areas tend to be poorly coordinated (Cervero 2000), resulting in the poor having the longest travel times and incurring more transfers (Ardila-Gomez 2012). This in turn diminishes their access to jobs and other economic opportunities (Carruthers et al. 2005). Research on women's travel in LAC and other developing regions has found that, on average, women tend to work closer to home, take shorter and more frequent trips, walk and take transit more often, trip chain (combining multiple trips together over the course of a day for a wider variety of purposes), travel more often during off-peak hours, and experience more safety concerns on transit systems and as pedestrians (Simicevic et al. 2016; Duchéne 2011; GTZ Sector Project Transport Policy Advisory Service 2007; Loukaitou-Sideris 2008; Osmond and Woodcock 2015).

\subsection{Land use and transport ${ }^{3}$}

Several models have been developed to explain the relationship between transport and land-use structures. Von Thünen's model, developed in the early nineteenth century, is the oldest representation based on a central location and its concentric impact on surrounding land use. The underlying principles of this model have been the foundation of several others where economic considerations, namely land rent and distance decay, are incorporated.

The Burgess concentric model, an adaptation of the Von Thünen model, was one of the first attempts to investigate spatial patterns at the urban level (Park and Burgess 1925) proposing a concentric representation from the central business district. Later developments include sector models, by which transport corridors, such as rail lines, public transit and major roads, are mainly responsible for the creation of sectors (Hoyt 1939). Multiple nuclei models argue that there is a progressive integration of a number of separate nuclei in the urban spatial structure with different levels of accessibility (Harris and Ullman 1945). Hybrid models combine the concentric effect of central locations (central and sub-central business districts) and the radial effect of a transport axis, all overlaid to form a land-use pattern (Isard 1956). Land rent theory, a geographic economic theory based on some of the urban growth ideas presented before, has been widely acknowledged in transportation research. This theory discusses how the price and demand for real estate change as the distance from the central business district increases. More specifically, there is a market where different urban activities compete for land use at

\footnotetext{
${ }^{3}$ This section summarizes material presented in Rodrigue et al. (2017).
} 
a location. The more desirable a location, the higher is its rent value. Transportation, through accessibility and distance decay, becomes a strong explanatory factor for the price of land and its use (McIntosh et al. 2017; Medda 2012; Debrezion et al. 2007).

The most recent trend in modeling land-use changes across space in response to transport interventions is based on cellular automata or dynamic land-use models, where the unit of analysis is represented as a cell or grid (Tobler 1979). This approach enables a higher level of spatial detail (resolution) in the analysis and links the changes in transportation structures to outcomes on the spatial structure of urban areas. According to authors such as Lau and Kam (2016), the cellular automata model outperforms the alternative model with only a distance function, confirming the importance of incorporating local attributes in modeling land-use changes.

As summarized in this section, urban transport investments can bring powerful changes to urban structures that affect individual-level decisions and location choices. Theories serve to better understand transport behavior and to identify the potential effects expected from urban transport interventions. Moreover, they provide multiple explanations through which changes in outcomes may happen. Overall, urban transport interventions modify travel costs, which then lead to a series of effects influencing work search and time allocation decisions. Moreover, travel costs constitute an important geographic attribute that affects the value households placed on land.

\section{Evidence on urban transport interventions}

The following section summarizes the evidence available from causal studies in urban transport. The chapter is organized by looking at different types of urban transport interventions, which have been implemented in different countries according to their context. In several cases, the outcomes of interest and methodologies of evaluation are similar across interventions, for example, the exploration of employment and land value effects and the use of difference-in-differences (DID) models are quite common in BRT and metro or light rail studies. In other cases, the nature of the intervention drives the outcome of interest and the methodological approach, such as the focus on environmental outcomes (e.g., pollution) arising from traffic restriction policies and the use of regression discontinuity designs (RDD) given the sharp policy changes.

\subsection{Evidence on bus rapid transit systems}

While designs can vary widely, BRT systems generally are bus-based systems that operate in dedicated lanes, with rapid service through the implementation of several operational features such as off-board payment, at-level bus boarding, intersection signal priority, passing lanes, and frequent service. ${ }^{4}$ The introduction of these systems has also generally been accompanied by government reforms of the bus sector that employ various public-private contracting schemes, or a mix of centralized planning and private investment and service operation. As these systems are considered a cost-effective and

\footnotetext{
${ }^{4}$ They can often transport as many passengers as most conventional light rail systems at a fraction of the cost and compare well with heavy rail systems, except when demand exceeds 50,000 passengers per hour per direction (Rodríguez and Mojica 2009).
} 
flexible approach to providing high-capacity and more environmentally sustainable transportation, they have grown rapidly around the world.

There is not a straightforward theoretical explanation of the impact that BRT systems can have on land values and land-use changes. Increases in property values may depend upon the quality of public transport systems and its subsequent ability to reduce travel times (Cervero and Kang 2011; Bocarejo et al. 2013). As BRT system designs and their associated travel time savings can vary widely, the effects on property values can also vary. As posited by Medda (2012), travel time reductions may also be valued differently by customers depending on the locations to which these new systems provide access. Moreover, the extent to which accessibility benefits translate into land values will depend on the sensitivity of users to improvements in access (Rodríguez and Mojica 2009). BRT systems and other mass transit investments that operate at surface or above ground can also have negative effects on property values and land use near the system due to nuisance effects such as noise, air pollution, and crowds of passengers. Finally, some studies hypothesize that the potential of BRT systems to increase property values may be lower compared to heavy and light rail systems due to their flexibility and perceived lower level of permanence and rigidity as an infrastructure service (Rodriguez and Targa 2004; Vuchic 2002).

Studies that examine the effects of BRT systems on property values and real estate development yield mixed results, ${ }^{5}$ but only a handful of papers use empirical strategies seeking to determine attribution. Perdomo (2011) uses propensity score matching to evaluate the impact on property values of TransMilenio, Bogota's BRT system, finding a positive impact on areas in the vicinity of the system. The absence of time-varying information, however, does not allow for controlling for unobservable characteristics that might affect the results. Rodríguez and Mojica (2009) evaluate the impact of the extension of TransMilenio on property asking prices. They exploit a DID estimation and find increases in prices in areas that were already served by the TransMilenio but that benefited from an extension, and detect no impact in areas that gain new access to the system. Their empirical approach lacks an analysis of how similar treatment and control groups were at baseline and a discussion about whether the parallel trends assumptions, required for DID to be valid, holds in this case.

The increased value of property is also theorized to stimulate land-use change by increasing the attractiveness of development or redevelopment of parcels near the stations (Rodríguez and Mojica 2009). Previously, vacant parcels may become more attractive to real estate investors, and those that are built up may become targets for more intensive development or infill. Timing of effects might be important: while land-price effects can be instantaneous, land-use changes tend to occur more slowly, partly due to institutional lags (e.g., securing building permits and zoning amendments) (Perez et al. 2003). The literature looking at the urban development effects or land-used changes from BRT investments is still scarce and also shows mixed results (Stokenberga 2014).

\footnotetext{
5 Some studies, using cross-sectional designs and hedonic price functions, conclude that properties that are closer to the bus rapid transit corridor have higher values (see Rodriguez and Targa, 2004, Mendieta and Perdomo, 2007, and MunozRaskin 2010, for Bogota; and Cervero and Kang, 2011, for Seoul, South Korea). Moreover, effects appear to be larger for non-residential properties that are closer to the bus rapid transit stops (Cervero and Kang 2011). These studies, however, do not consider that there might have already been differences in prices between areas that are closer and further away from bus rapid transit stations even before the system was opened, thus making attribution difficult.
} 
Again, most of this literature is based on before-and-after comparisons, or cross-sectional analysis exploiting distance to the system, without explicit consideration of the counterfactual scenarios. ${ }^{6}$ The only study identified here that offers a DID estimation is that of Bocarejo et al. (2013), which shows that areas served by Bogota's TransMilenio have higher population growth than areas without access to the system, particularly feeder areas, but that there are no significant changes in land use. ${ }^{7}$

By reducing transport costs and improving accessibility, BRT investments may also have effects on facilitating access to markets and services. Along these lines, multiple studies, mostly conducted in developed countries, have analyzed the impact of urban transit investments on employment outcomes, but the majority are non-causal. ${ }^{8}$ Among recent studies seeking to address causality, Scholl et al. (2018) rely on a combination of individual-level DID and area-level propensity score-based overlap analyses to evaluate the Metropolitano BRT of Lima, Peru. They find that several years after the introduction of the system, there are positive effects on employment outcomes (employment, formal employment, hours worked, and monthly labor income) for individuals living close to the BRT stations, but not for those who live close to the feeder lines. Tsivanidis (2018) looks at the aggregate and distributional effects of TransMilenio. Based on work featuring gravity equations for commute flows (Ahlfeldt et al. 2015), he proposes a new reduced-form methodology derived from general equilibrium theory based on "commuter market access," arguing that distance-based approaches might be misleading in capturing the intensity of treatment. To address the non-random route placement, he uses instrumental variables estimation exploiting historic data on the tram system and engineering estimates of the cost to build BRT systems on different types of land. The author finds that while the system caused increases in welfare and output larger than its cost, gains accrued slightly more to high-skilled workers. The analysis of mechanisms suggests a potential increase in residential segregation by skills.

Another recent strand of the BRT literature has analyzed the effects of such systems on pollution. Bel and Holst (2018) study the effect of Mexico City's Metrobus on air pollution emissions. Using DID and quantile regression techniques, they estimate the atmospheric concentration of pollutants in Mexico City between 2003 and 2007 to assess the impact of the introduction of the Metrobus. They conclude that the BRT system constitutes an effective environmental policy, reducing emissions of $\mathrm{CO}, \mathrm{NO}_{\mathrm{X}}, \mathrm{PM}_{2.5}$, and $\mathrm{PM}_{10}$.

Limited access to safe transportation is one of the greatest challenges to labor force participation faced by women in developing countries, reducing their participation

\footnotetext{
${ }^{6}$ For example, Knight and Trygg (1977) concluded that exclusive bus lanes in several North American cities had no impact on either residential or commercial development, while Mullins et al. (1990), using a before-and-after comparison, found that the bus rapid transit system in Ottawa, Canada, had some effect on land development in areas surrounding stations. Cervero and Kang (2011) use distance to the bus rapid transit system in a regressions framework with controls to conclude that bus rapid transit improvements in Seoul prompted property owners to convert single-family residences to higher-density apartments and condominiums.

7 Land-use changes are approximated by housing, commercial, and office-built areas.

8 Non-causal and can be classified in three groups. The first focuses on predicting changes in access to employment opportunities from bus rapid transit systems in terms of ease of access to jobs (Dutta and Henze 2015; Delmelle and Casas 2012; Bocarejo and Oviedo 2012; Bocarejo et al. 2016). The second group empirically estimates employment effects based on correlation studies to show that proximity to a bus or subway stop, or transit service frequency, is correlated with lower levels of unemployment (see Sanchez 1999, and Sanchez et al. 2004, for the USA; and Oviedo-Dávila 2017, for Bogota). The third group uses a before-and-after approach to show that growth is largest near downtown stations of bus rapid transit corridors, particularly for white-collar and high-wage employment (Guthrie and Fan 2016).
} 
probability by $15.5 \%$ points (ILO 2017). Two recent studies looking at employment outcomes of bus services show that the effects are especially strong for women. Martinez et al. (forthcoming) look at both BRT and metro systems in Lima and explore the differential effects on employment by gender. Using DID regressions looking at comparable areas (selected through overlap in propensity score at the area level) that are closer and farther away from the systems, they show increases in the probability of being employed among women living closer to the systems and no significant changes for men. Changes are driven by women not previously in the labor market and, although there is an increase in earnings per hour, no improvements are observed in job quality. AbuQarn and Lichtman-Sadot (2019) provide evidence of a trade-off between investment in education and time allocated to work by women after the introduction of bus services in Arab towns in Israel. They support their identification strategy based on the argument that bus line introductions and schedule changes were random due to the long bureaucratic approval processes.

\subsection{Evidence on light rail and subway systems}

Urban light rail and subway systems are expensive enough that these projects generally require large subsidies. To justify these subsidies, proponents often assert the ability of these systems to have a transformative effect on the city and to encourage employment growth (Gonzalez-Navarro and Turner 2018). However, the causal evidence is limited regarding such transformative effects. This section focuses on the small set of papers that attempt to solve the causality problem caused by the non-random assignment of these systems and their stations.

Baum-Snow and Kahn (2000) study the impact of new rail transit on usage and housing values. They exploit variation in transit access changes among census tracks within five major cities in the USA that upgraded their rail transit systems in the 1980s, using distance as a proxy for transit access. The authors find that rail transit improvements lead to increased mass transit use for commuting, but to a small capitalization of transit infrastructure into housing prices and rents. In related research, Gibbons and Machin (2004), for the case of the London Underground and Docklands Light Railway in South East London, and Billings (2011), for the case of the new light rail line in Charlotte, North Carolina, show increases in prices in areas closer to the systems using DID approaches. More recently, Dorna and Ruffo (2017), using a DID approach combined with matching analysis, find that the electrification of a light rail suburban line in Buenos Aires had positive effects on housing prices around the areas of influence of the stations. Using a synthetic control methodology, they also find that the increased reliability of the service had large effects on ridership.

While these studies provide evidence regarding the effects of mass transit on property values, they do not provide information on the relationship between light rail and subway systems and the growth of cities. If these systems affect urban growth, those effects will appear both near and far from the stations and might take more time to appear. Such citywide effects are, by construction, not captured by a DID methodology, as noted by Gonzalez-Navarro and Turner (2018), who studied the relationship between the extent of a city's subway network, its population, and its spatial configuration in the 632 largest cities in the world. For this, they construct panel data describing the subway systems in 
these cities, their population, and measures of centralization calculated from night lights data. Their evidence suggests that when big cities build subways, the subways have at most a small effect on urban population growth. However, they find that subways allow the central cores of large cities to spread out and reorganize activity in the cities, suggesting that when transportation costs fall, economic activity can spread out.

Regarding employment, Holzer et al. (2003) exploit the exogenous change in accessibility to employment brought by the expansion of the Bay Area Rapid Transit System (BART) (including heavy rail and subway). Using a DID approach, the authors estimate the impact of the expansion of BART on the propensity of suburban firms to hire minority populations, finding sizable increases in the hiring rates of Latino workers but no increases in the hiring rates of African-Americans. In another study in the United States, using historical data on manufacturing establishments from 1850 to 1870, in DID and instrumental variables models, Atack et al. (2008) find that the introduction of the railroad increased the number of factories and thus employment. Results also show that firms located in counties that gained rail access were more likely to employ women relative to men. More recently, the impact of an exogenous shock from Hurricane Sandy, which shut down a portion of New York's metro system (the R train) in 2013, was exploited to estimate the effect of the system on access to employment (Tyndall 2017). Findings show that living next to the $\mathrm{R}$ train during the shutdown resulted in an overall increase in the probability of being unemployed, and that effects were lower for individuals who had access to a vehicle and much higher for those who were transit dependent. On the gender front, Asahi (2016) exploits fixed effects models to show that increased proximity to the subway network in Santiago, Chile, is associated with higher employment rate and hours of work especially for women.

Another important strand of the literature looks at impacts on air pollution. Chen and Whalley (2012) use a sharp RDD to examine rail transit ridership on the opening day of a new rail transit system in Taipei, China. The assumption behind this design is that in the absence of opening the Taipei Metro, air quality would have changed smoothly for that day (i.e., air pollution levels on the days just before the opening of the Taipei Metro form a valid counterfactual for air pollution levels in Taipei on days just after the opening of the Taipei Metro), conditional on differences in weather, a host of time-specific fixed effects, and a very flexible smooth time trend. The authors found that the opening of the Taipei Metro reduced $\mathrm{CO}_{2}$ air pollution by $5-15 \%$, but they found little evidence that groundlevel ozone pollution was affected by the opening of the Metro. Goel and Gupta (2015) use a similar strategy to measure the effects of the Delhi Metro in India on air pollution. The authors exploit the sharp discontinuities in metro ridership resulting from each extension of the rail network and examine whether they coincide with corresponding discontinuities in pollutant measures. They found evidence of large reductions in $\mathrm{NO}_{2}$ and $\mathrm{CO}_{2}$ levels.

\subsection{Evidence on cable cars}

Cable cars are mainly touristic attractions in rich western countries, but in LAC cities they have been implemented as transport systems to connect isolated low-income neighborhoods with the city center. Cable cars offer multiple advantages over subways or light rails systems. They can be built in a shorter amount of time, do not require the displacement of large groups of people, and seem more suited for cities with mountainous 
geographies (The Economist 2017). However, these systems tend to be heavily subsidized and do not have the same capacity as other massive transport systems. The first cable car designed as a transport system in LAC opened in Medellín, Colombia, in 2004. Since then, Caracas (Venezuela), Cali (Colombia), Mexico City (Mexico), Rio de Janeiro (Brazil), and La Paz (Bolivia) have built similar systems.

Notoriously, all causal evaluations available for cable cars pertain to cities in the LAC region, namely Medellín and La Paz. ${ }^{9}$ Cerdá et al. (2012) examine the effects of the Metrocable in Medellín on violence, based on homicide reports at the neighborhood level and household surveys. The empirical strategy compares neighborhoods that are serviced by the Metrocable versus comparable neighborhoods not serviced by this system (obtained through propensity score-matching techniques) before and after completion of the transit project. Their findings show that the decline in homicide rates was greater in treated neighborhoods and that resident reports of violence also decrease in the proximity of the system. Using more detailed geo-coded information, Canavire-Bacarreza et al. (2016) also found reduced homicide rates in neighborhoods served by the Metrocable.

Bocarejo et al. (2014) also studied the effects of the Metrocable in Medellín, looking at changes in accessibility to jobs, travel time savings and costs, and housing values. The authors use data from origin-and-destination (OD) surveys before and after the project's implementation. Their results show that the access provided by Metrocable to the main employment centers doubled the number of job opportunities reachable by people in the area of influence of the project. However, they did not observe large changes in reported travel time savings and costs. Moreover, the authors did not find a statistically significant relationship between the Metrocable and housing costs.

It is often assumed that cable cars, as well as other urban transport systems, lead to travel time savings, but few impact evaluation studies quantify these savings. SuárezAlemán and Serebrisky (2017) conducted a quantitative estimation of travel time savings arising from Mi Teleférico, the cable car system in La Paz. The authors used individuallevel, OD surveys and compared travel times between trips, with the same origin-destination pair that were made on Mi Teleférico versus those that were made on alternative transport systems. Their findings suggest that, on average, Mi Teleférico reduced travel times by $22 \%$.

More recently, Martinez et al. (2018) estimated the impact of Mi Teleférico on changes in household-level transport expenditures, individual time allocation decisions, and employment outcomes using cross-sectional data. Given that stations were located in an ad hoc manner, similar to an exogenous shock for nearby households, and that households cannot easily manipulate their location in the short term (particularly property owners), the identification strategy exploits distance to the closest station of the Mi Teleférico system as an instrumental variable to predict the use of the system. The results point toward a transport modal shift, as treated households report larger expenditures

\footnotetext{
${ }^{9}$ Following non-causal methodologies, the cable car of Medellín (Metrocable) has been the most studied in the literature. Evidence on this system suggests that it is correlated with improvements in urban integration and the modernization of neighborhoods (Brand and Dávila 2011; Goodship 2015), accessibility and improved citizen security, particularly for women (Heinrichs and Bernet 2014), improved quality of life (Roldán and Zapata 2013), increased employment opportunities for the poor (Bocarejo et al. 2014), and reduced emissions (Dávila and Daste 2012).
} 


\section{T I ME LINE OF DRIVING RESTRICTIONS}

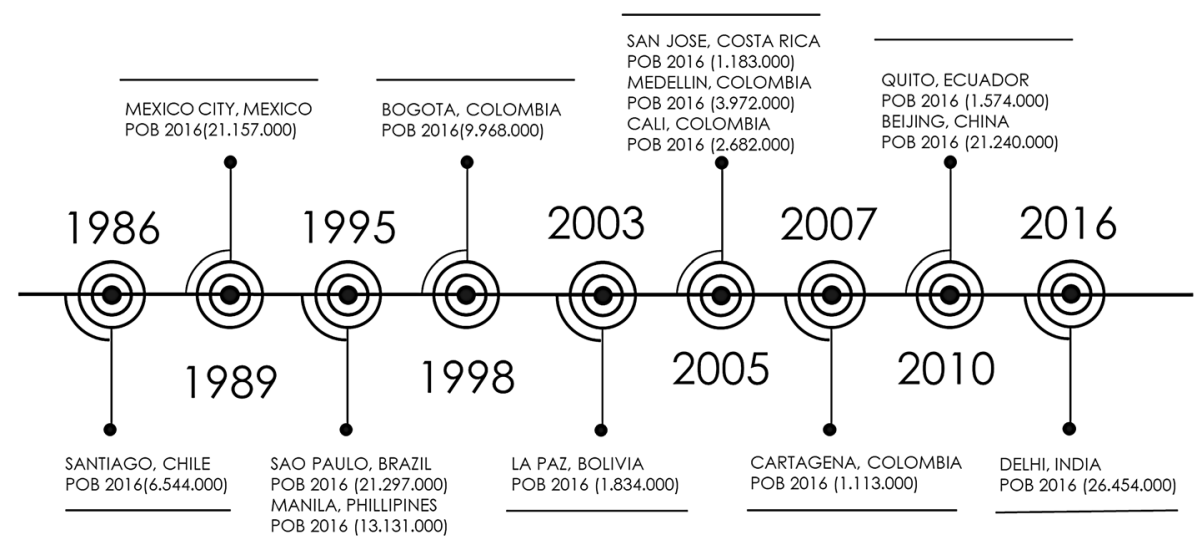

Fig. 1 Timeline of driving restriction policies around the world. POP indicates the size of the population for each city in 2016 (Source: Prepared by the authors)

on public transportation and lower expenditures on private transportation. In terms of time allocation, there is a significant reduction in transport time and an increase in the time devoted to educational and recreational activities. Finally, there is evidence of increases in self-employment activities and associated increases in labor income.

\subsection{Evidence on driving restrictions}

Currently, capital cities in LAC exceed the recommended annual WHO limits for $\mathrm{PM}_{10}$ and $\mathrm{PM}_{25}$ emissions (WHO 2017) while also ranking poorly on the Waze (2016) driver satisfaction index and the TomTom (2017) traffic index. To deal with both pollution and congestion levels, and to ultimately try to influence the mode of transport choice of the population, several cities around the world have tried policies to curb emissions and/ or reduce traffic congestion during peak hours. These policies include large investments in public transport, designated lanes for high-capacity vehicles, and congestion pricing schemes. However, these initiatives are either costly or politically charged for city governments to easily implement. Several cities, primarily in LAC, have opted for a less expensive alternative: vehicle driving restrictions. LAC has actually been the pioneer on this issue (Fig. 1). Following the restrictions imposed in Santiago, Chile in 1986, several LAC cities followed, including Mexico City, São Paulo, La Paz, San José, Quito, and several cities in Colombia. More recently, Delhi, India, and Beijing, China, have implemented similar approaches.

Normally, these restrictions ban the use of private light vehicles during specific times of a weekday in certain areas of a city, based on a given rule like the last digits of the vehicles' license plates. The restrictions are in place during rush hours in both the morning and the evening. Compliance with the program comes from enforcement either by police officers on the street or traffic cameras, and hefty fines are imposed for violations. ${ }^{10}$

\footnotetext{
10 The most well known of these programs in LAC is "Hoy No Circula" ("Today You Do Not Travel"), which was started in 1989 in Mexico City to curb pollution within the metropolitan area. Santiago, Chile, introduced a license plate-based restriction in 1986 for vehicles lacking catalytic converters and later expanded it to all vehicles. São Paulo, Brazil, started restricting drivers in 1996 following the initiative in Mexico City, and so did Bogota, Colombia, in 1998, although mostly to deal with traffic congestion. Other cities in Colombia followed the example of the capital, including Cali, Cartagena, and Medellin, as did other LAC cities such as San Jose (Costa Rica), Quito (Ecuador), and La Paz (Bolivia).
} 
Several studies have used empirically robust methodologies to assess the effectiveness of these types of restrictions, and their findings have been mostly disappointing. Permanent restrictions do not have a lasting effect on reducing pollution or traffic and might even induce households to buy a second highly polluting car to circumvent the restriction completely. ${ }^{11}$ Studies of the "Hoy No Circula" program in Mexico City, such as Eskeland and Feyzioglu (1997) concluded that the driving restrictions increased gasoline use, most likely from a second car in the household. Davis (2008) found an increase of $20 \%$ in the car fleet with a decrease in bus ridership and an increase in car sales, while also finding that it had no discernible effect on air quality. Gallego et al. (2013) found that households adjusted their vehicle stock in a little less than a year and thus the benefits of the restrictions disappeared by the second year. Davis (2017) suggests that expanding the restriction to Saturdays did not reduce air pollution, as households relied on other private car trips. Finally, Blackman et al. (2018b) used a contingent valuation methodology for the willingness to pay (WTP) to avoid the traffic restriction. They found an average annual WTP equivalent to US $\$ 130$ per vehicle, which represents up to $2 \%$ of a driver's annual income.

Methodologies for assessing the impact of these restrictions typically exploit the timing of the intervention. Studies of the impact on pollution of Mexico City's restrictions use air quality monitoring stations throughout the city and an RDD centered around the date of implementation, while also controlling for environmental covariates and flexible polynomial adjustment terms (Davis 2008, 2017; Gallego et al. 2013). This methodology has been replicated in other studies (see Blackman et al. 2018a, for a review of developing countries studies) and the results are comparable to the one for Mexico City's program. Studies of the programs in Bogotá, Santiago, São Paulo, and Quito have found short-term gains, but mixed or even negligible long-term results because drivers adopt strategies to circumvent the restriction (Troncoso et al. 2012; Bonilla 2016; Carrillo et al. 2016; Zhang et al. 2017). In sum, the existing literature suggests that driving restrictions can work for short-term pollution emergencies, but that using driving restrictions as long-term fixes for pollution and congestion must take into account available public or non-pollutant substitutes and behavioral responses by drivers.

\subsection{Evidence on transport network companies}

In recent years, transport network companies (TNC, also known as ride-sourcing companies) have received remarkable attention from consumers, the media, and policymakers. These types of companies have emerged as app-based, on-demand ride services and they have generated a debate over their role in urban transport. TNC have become more common over the last decade, with small local or regional services giving way to national and global companies. Examples include Car2go, Zipcar, ReachNow, Via, Cabify, Lyft, and Uber.

The transport sector of many cities (those in LAC included) is now experiencing a high level of disruption with the introduction and evolution of technology and transport

\footnotetext{
${ }^{11}$ One of the ways the restriction has shown an unintended effect on the secondary car market is the inclusion of the license plate numbers in all advertisements, so households can choose a car with a license plate that has a restriction on a different day.
} 
services. As these new layers of technology-based transportation options spread, it is important to understand how they affect the transportation systems and society. The literature on this topic appears to be very limited, in part due to their novelty and lack of open data on these services. In addition, there are difficulties in constructing valid counterfactual scenarios, given that in many cases transport network companies are introduced in whole cities or countries at the same time.

Ride sourcing has been mainly compared with taxis. This is primarily because both services involve passengers paying a fee for the travel. However, there are many differences between them, including the use of technology, labor market differences, and government regulations. In the different countries where ride-sourcing companies have tried to enter, there has been resistance by current providers (mostly taxis) and controversy because the new companies disrupt the industry, competing and taking away many customers from taxis. Rayle et al. (2014) compare ride-sourcing and traditional taxis in San Francisco using an intercept survey. Their findings suggest that ride sourcing meets a latent demand for urban travel, appealing to generally younger, well-educated users looking for short wait times and fast point-to-point service, while avoiding the inconveniences of driving like parking, or restrictions on drinking and driving.

One of the main concerns with the rise of ride-sourcing companies has been the effect that they may have on traffic congestion, especially considering that the areas in which they operate are large cities with heavy traffic. Using a DID approach, Li et al. (2017) found that the entry of Uber into the USA market significantly decreased traffic congestion time, congestion costs, and excessive fuel consumption. The authors argue that ride-sharing services have the potential to reduce car ownership, shift the traffic mode from single occupancy to ride sharing, and delay travel plans during peak hours, thus reducing overall traffic congestion in an urban area. This is to the best of our knowledge the only study that attempts to show a causal effect of the entry of a TNC.

\subsection{Incentives to increase demand of urban transport systems}

As urban transport systems consolidate their operations, new evaluation questions emerge related to the operational aspects of the system. From the operators' perspective (in several cases a private sector actor), some of these questions could relate to what the most appropriate tariffs are to maximize the demand of the system or what type of promotion strategies could be most effective to incentivize its use, among others. From a policy perspective, incentivizing demand could be key to promoting a modal shift to transport systems that are more environmentally friendly. It could also be relevant to understand how transport systems can maximize social inclusion effects through welldesigned and targeted subsidies. This section presents evidence around some of these questions.

\subsubsection{Willingness-to-pay studies}

As important as it is to know the effects of different urban interventions, it is also important to understand how much people are willing to pay for those interventions. Several studies, the majority in developed countries, have looked at the WTP of travelers or consumers for different transport services or attributes. In several 
cases, this information is elicited through experimental designs (stated preferences), while in others it is based on observations of actual behavior or choices (revealed preferences approach).

Some studies have looked at the WTP to reduce travel time in the context of toll highways, which has been used to guide the design of congestion pricing or time of day pricing programs. The main idea behind these estimations is to obtain the value of time or the amount of money that a respondent would be WTP in tolls for 1-h time savings to keep the respondent's transport choice unchanged (Brownstone et al. 2003). Calfee and Winston (1998) applied stated preference models to a sample of drivers who regularly drove to work in major metropolitan areas of the USA. They found that the WTP was surprisingly low (between $\$ 3.5$ and \$5 per hour) and insensitive to travel conditions and to how toll revenues were used. Using revealed preference data, Brownstone et al. (2003) estimated that users have a median WTP of $\$ 30$ to reduce travel time by $1 \mathrm{~h}$ on San Diego's Route I-15, which highlights the fact that stated preference studies generally yield lower values than revealed preference studies (Wardman 2001). For Route 91 in Southern California, Lam and Small (2001) estimated the value of time to be between \$19 and \$24 per hour depending on model specification. They looked at day pricing, which might explain the variation in results in comparison to Brownstone et al. (2003) who looked at congestion pricing.

WTP studies have also been applied to value improvements in the quality of transport services. Molin and Timmermans (2006) and Khattak et al. (2003) evaluated the value for consumers of different information aspects that can be included in web-enabled or electronic public transport information systems in the Netherlands and the USA, respectively. Their results indicate that travelers are willing to pay for better quality and more interactive information systems. Eboli and Mazzulla (2008) estimated the WTP for improving the quality levels of a bus service among Spanish students. Their results showed that the maximum valuation corresponded to service frequency and the minimum value pertained to information at bus stops. More specifically, users would pay an increase of $44 \%$ in weekly and monthly cards for more service frequency. In a similar vein, Worku (2013) examined the willingness to use and pay for improved public transport services in the United Arab Emirates. The results suggest that residents are willing to use and pay higher fees for public buses, provided that the quality of service is improved.

Another way of using WTP results is to characterize the demand of existing or new transport systems. Results from multiple studies highlight the heterogeneity in WTP across individuals, which is key to improving the design and targeting of certain transport interventions. For example, for certain settings, females seem to value more the expressways when compared to men (Senbil and Kitamura 2004). Higherincome persons are willing to pay more to reduce travel time because of their greater opportunity cost (Markose et al. 2007). Individuals who are more aware of environmental issues are more likely to use public transport (Carson 2000; Lee and Cheah 2014), and those with more children and who are older save travel time by using more expensive or shorter routes (Asensio and Matas 2008). 


\subsubsection{Experiments with subsidies to increase demand and encourage employment search}

Subsidies for public urban transport have been adopted, both in developed and developing countries, to make transport more affordable. As these subsidies usually encourage the use or more frequent use of transport systems, they might also facilitate access to services and economic opportunities. Phillips (2014) studied whether transportation costs constrained job searches in urban low-wage labor markets. He provided transit subsidies to randomly selected clients of a non-profit employment agency in Washington, DC. The subsidies generated a large, short-run increase in job search intensity for the transit subsidy group relative to a control group receiving standard job search services but no transit subsidy. In the first 2 weeks, individuals assigned to the transit subsidy group applied and were interviewed for $19 \%$ more jobs than those not receiving subsidies. These results provide experimental evidence in support of the theory that search costs over time can depress job search intensity, contributing to persistent urban poverty in neighborhoods far from job opportunities. Similar findings have been obtained by Franklin (2017) looking at the case of young job seekers who live far from the center of Addis Ababa, Ethiopia. The author concludes that search costs impose significant constraints to find employment, as experimentally treated individuals increase job search intensity and are more likely to find good and permanent jobs.

\section{Discussion, policy implications, and future avenues of research}

This paper summarizes the existing knowledge arising from causal studies looking at the impact of urban transport systems. Driving restriction interventions are also discussed, given their potential to affect the demand for passenger transport systems. The review highlights the increasing number of causal evaluations that have emerged in this area, probably following the important growth in public and private investments in the sector in response to congestion, pollution, and transport safety problems in many urban areas around the world.

The available literature shows that studies have been concentrated on certain types of interventions and the majority have been conducted in developed countries. The evidence on BRT systems and subways, as well as on driving restrictions, is among the most developed. In contrast, there are still few studies of recent interventions such as TNC or ride-sharing systems. Moreover, there is great potential for conducting evaluations on interventions that seek to improve the operational efficiency of systems and those that seek to promote behavioral changes in users. The review also highlights that there are still few causal studies in the LAC region. Those identified are concentrated on evaluating traffic restriction policies and BRT systems. From an external validity point of view, creating more evidence for the region is essential to guide policymaking.

In terms of methodological approaches, many studies in this literature, particularly the oldest ones, suffer from several limitations when addressing causality. Multiple studies rely on before-and-after comparisons without considering the counterfactual scenario. Others have only used distance to the system, but cross-sectional comparisons across space do not allow for controlling for key time-invariant unobservable characteristics. A smaller number of studies use DID methods, but several papers lack a proper discussion of the validity of parallel trend assumptions underlying this causal approach. In recent 
years, some studies have moved toward combining matching with DID techniques to reduce some of these concerns. In other cases, particularly for environmental outcomes that can change quickly over time, the strategies have been based on RDD. This review only finds a few cases using experimental designs, and this is probably due to the difficulties in randomizing many of the elements around transport systems. More recently, a few authors have proposed the use of quantitative general equilibrium frameworks given the expected impacts in the entire network and the difficulties in identifying pure treatment and control groups.

Regarding the main lessons learned about impact, BRT has been the most studied, but the evidence has been mixed on both prices and land-use changes. This could be due to the different evaluation methods used and how (or whether) they have approached causality. It could also respond to the fact that these systems might not be perceived to be permanent by the real estate market, as they could be moved or changed over time, and their quality differs across countries and regions. The most recent literature tackling causality suggests that BRT systems could have an impact on increasing land values. In the case of subways and light rail, results seem to be more conclusive, suggesting positive effects on land values. The evidence also indicates that subways may lead the central cores of large cities to spread out by reorganizing activity in the cities.

There are still few studies exploring the socioeconomic impact and displacement effects arising from BRT and subway or light rail systems, possibly due to data limitations, including the difficulty of following households over time and of selecting credible comparison groups. Findings in this area are mixed, but those arising from recent causal studies seem to indicate that, to the extent that accessibility gains are large, these investments could have effects on employment, both by increasing the probability of being employed. Finally, for environmental outcomes, the studies conducted in this area are probably the most rigorous and point to positive environmental effects, particularly reductions in pollution.

For cable cars, although these systems are becoming increasingly popular in the region, the causal evidence is limited to the case of Medellín (Metrocable) and La Paz (Mi Teleférico). There is evidence that these systems do indeed bring important travel time savings and thus have impacts on time allocation decisions and employment outcomes. They also seem to affect the development of neighborhoods, particularly those that have accessibility gains, suggesting impacts on crime reduction.

Regarding driving restrictions, the existing literature suggests that these policies can work for short-term pollution emergencies, but that using driving restrictions as longterm fixes for pollution and congestion must take into account behavioral responses by drivers. Studies of such programs in Bogota, Santiago, São Paulo, and Quito have found short-term gains, but mixed or even negligible long-term results because drivers adopt strategies to circumvent the restriction, by buying a second, sometimes highly polluting car.

In the case of TNC, which are increasingly being used in urban areas, the only available causal study, which is for the USA, concludes that ride-sharing services have the potential to reduce car ownership, shift the traffic mode from single occupancy to ridesharing, and delay travel plans during peak hours, thus reducing overall traffic congestion in an urban area. The scarcity of studies in this high-growth area points to the need 
to develop studies that can evaluate the causal effect of the entry of these companies in a market.

WTP studies have been conducted for a long time and will continue to be relevant to guide the design of new transport services and to better understand travelers' behavioral responses. Experiments in this area need to be carefully designed to avoid any bias in the responses. Findings show that people are willing to pay to reduce travel time and to use public transit systems under certain conditions. The evidence reviewed offers insights into the establishment of tolls, the improvement of quality attributes in bus services, and the design of web-enabled transport information, among others. Results show that contingent valuation is affected by personal characteristics, by the system, and by the environment surrounding the users. For example, people are willing to pay higher fees to use public buses provided that service quality is improved. Also, concerns about the environment, previous experience with urban transport, and problems of insufficient parking might affect the demand of these systems.

Subsidies for public urban transport have been adopted in both developed and developing countries to make these systems more affordable, particularly for lower-income populations. A few experimental studies in this area analyze whether transportation costs constrain job search in urban low-wage labor markets and access to formal jobs. Results from studies in Africa and the USA show that transit subsidies can generate increases in job search intensity and in the probability of finding permanent work.

The review highlights the broad portfolio of urban transport interventions that are being implemented across the globe to reduce mobility problems. Measured impacts show that beyond the reduction in travel times, which is usually what motivates these interventions, there are important socioeconomic effects that need to be quantified and incorporated in cost-benefit considerations. Some types of interventions seem to have more conclusive results, but it is also evident that different segments of the population and different areas, based on their geographic location, socioeconomic characteristics, and other factors, might benefit from these policies in various ways. As results could be context specific, more studies are needed to build a strong base of evidence that has external validity and that can appropriately guide the design and implementation of future transport projects. Finally, although urban transport investments have the potential to promote poverty reduction and social inclusion, more targeted policies are needed to fully achieve this goal.

From an analytical perspective, this review confirms that there is ample room to generate causal evidence on the impact of urban transport investments, not only in LAC but also in other developing countries. It is important to acknowledge that these evaluations can take several years to be concluded, as they need to follow the timing of the construction and implementation of transportation systems. Moreover, as these systems cannot be randomly located across space, many of these studies will continue to rely on quasi-experimental designs. These two aspects have probably contributed to reducing the interest of academics in exploring this field. However, to the extent that studies can present robust evidence to justify their underlying causal assumptions, they will be able to provide important contributions. The knowledge agenda is now increasingly moving toward using non-traditional sources of data, such as data generated by mobile phone calls and apps, digital sensors, cameras, and satellite information, among others. 
Administrative data from transport operators could also be quite valuable, and have not been used frequently for causal evaluation. These new sources of data raise the possibility of conducting retrospective evaluations and reducing the burden and risks associated with primary data collection. In addition, in the presence of high-frequency data, and to the extent that transport interventions bring important accessibility changes to large areas, other methodological approaches such as synthetic control methods might be explored. Moreover, general equilibrium models offer the possibility of structurally measuring the full and indirect effects of transport system interventions in a connected network. Evaluations related to "soft" components, such as optimal tariffs and subsidies as well as other incentives to increase demand, are another promising area of analysis. These studies could be undertaken using experimental designs and bring about results in the short term that would allow operators to improve their services. Finally, given the wide variation in the quality and reliability of services, much research is needed on the impact of service quality on elements such as ridership, employment, and pollution.

\section{Abbreviations}

BART: Bay Area Rapid Transit System; BRT: Bus Rapid Transit; DID: difference-in-differences; LAC: Latin America and the Caribbean; PPP: public-private partnership; RDD: regression discontinuity design; TNC: transport network companies; WHO: World Health Organization; WTP: willingness to pay.

\section{Acknowledgements}

The opinions expressed in this publication are those of the authors and do not necessarily reflect the views of the InterAmerican Development Bank, IDB Invest, their respective boards of directors, or the countries they represent.

\section{Authors' contributions}

The authors contributed to the writing of different sections within the draft and all of them participated in the revision and editing of the final draft. All authors read and approved the final manuscript.

\section{Funding}

No funding was received by any author to produce this study.

Availability of data and materials

All data and materials used in the paper are publicly available and references have been provided for every case.

Competing interests

The authors declare that they have no competing interests.

\section{Author details}

${ }^{1}$ IDB Invest, Washington D.C., USA. ${ }^{2}$ Inter-American Development Bank, Washington D.C., USA. ${ }^{3}$ Universidad de San Andrés, Victoria, Argentina. ${ }^{4}$ Fox International Fellow MacMillan Center for International and Area Studies, Yale University, New Haven, CT, United States.

Received: 28 August 2019 Accepted: 31 October 2019

Published online: 14 November 2019

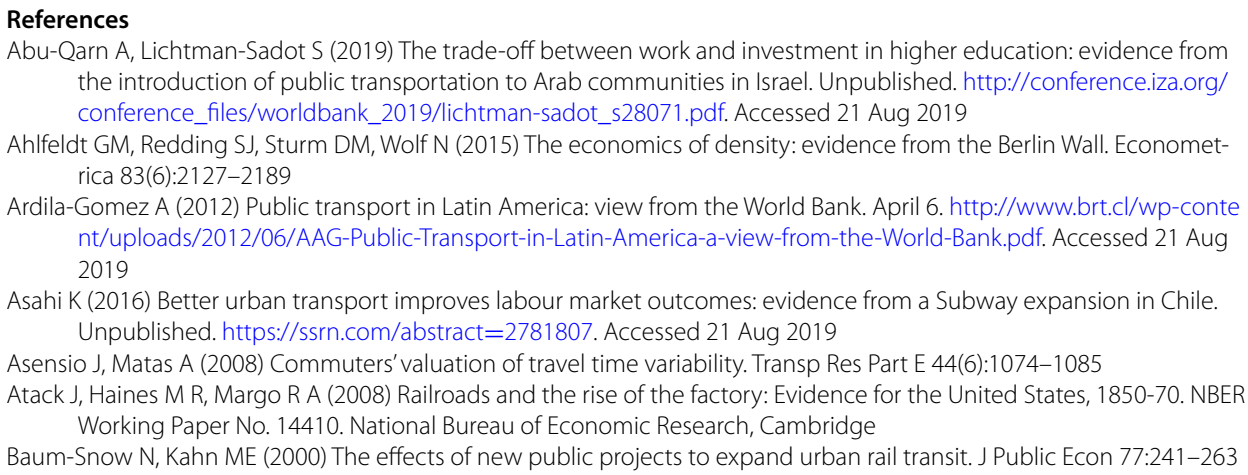
the introduction of public transportation to Arab communities in Israel. Unpublished. http://conference.iza.org/ conference_files/worldbank_2019/lichtman-sadot_s28071.pdf. Accessed 21 Aug 2019

Ahlfeldt GM, Redding SJ, Sturm DM, Wolf N (2015) The economics of density: evidence from the Berlin Wall. Econometrica 83(6):2127-2189

Ardila-Gomez A (2012) Public transport in Latin America: view from the World Bank. April 6. http://www.brt.cl/wp-conte nt/uploads/2012/06/AAG-Public-Transport-in-Latin-America-a-view-from-the-World-Bank.pdf. Accessed 21 Aug 2019

Asahi K (2016) Better urban transport improves labour market outcomes: evidence from a Subway expansion in Chile. Unpublished. https://ssrn.com/abstract=2781807. Accessed 21 Aug 2019

Asensio J, Matas A (2008) Commuters' valuation of travel time variability. Transp Res Part E 44(6):1074-1085

Atack J, Haines M R, Margo R A (2008) Railroads and the rise of the factory: Evidence for the United States, 1850-70. NBER Working Paper No. 14410. National Bureau of Economic Research, Cambridge

Baum-Snow N, Kahn ME (2000) The effects of new public projects to expand urban rail transit. J Public Econ 77:241-263 
Beckx C, Arentze T, Int Panis L, Janssens D, Vankerkom J, Wets G (2009) An integrated activity-based modelling framework to assess vehicle emissions: approach and application. Environ Plan B Plan Des 36(6):1086-1102

Bel G, Holst M (2018) Evaluation of the impact of bus rapid transit on air pollution in Mexico City. Transp Policy 63:209-220

Billings SB (2011) Estimating the value of a new transit option. Reg Sci Urban Econ 41:525-536

Blackman A, Li Z, Liu A (2018a) Efficacy of command-and-control and market-based environmental regulation in developing countries. Annu Rev Resour Economics 10:381-404

Blackman A, Alpízar F, Carlsson F, Rivera-Planter M (2018b) A contingent valuation approach to estimating regulatory costs: Mexico's Day without driving program. J Assoc Environ Resour Econ 5(3):607-641

Boarnet M (2007) Conducting impact evaluations in urban transport. Povery reduction and economic management doing impact evaluation series no. 5. World Bank, Washington DC

Bocarejo JP, Oviedo DR (2012) Transport accessibility and social inequities: a tool for identification of mobility needs and evaluation of transport investments. J Transp Geogr 24:142-154

Bocarejo JP, Portilla I, Pérez MA (2013) Impact of Transmilenio on density, land use, and land value in Bogotá. Res Transp Econ 40(1):78-86

Bocarejo JP, Portilla I, Velásquez JM, Cruz MN, Peña A, Oviedo DR (2014) An innovative transit system and its impact on low income users: the case of the Metrocable in Medellín. J Transp Geogr 39:49-61

Bocarejo JP, Portilla I, Meléndez D (2016) Social fragmentation as a consequence of implementing a Bus Rapid Transit system in the city of Bogotá. Urban Stud 53(8):1617-1634

Bonilla JA (2016) The more stringent, the better? Rationing car use in Bogota with moderate and drastic restrictions. Policy Research Working Paper No. 7846. World Bank, Washington, DC

Brand P, Dávila JD (2011) Mobility innovation at the urban margins: Medellin's Metrocables. City 15(6):647-661

Brownstone D, Ghosh A, Golob T, Kazimi C, Amelsfort DV (2003) Driver's willingness-to-pay to reduce travel time: evidence from the San Diego I-15 Congestion Pricing Project. Transp Res Part A Policy Pract 37(4):373-387

CAF (2010). Observatorio de Movilidad Urbana para América Latina. Corporación Andina de Fomento. http://publicacio nes.caf.com/media/1130/0.pdf. Accessed 30 July 2018

Calfee J, Winston C (1998) The value of automobile travel time: implications for congestion policy. J Public Econ 69:83-102

Canavire-Bacarreza G, Duque J C, Urrego J (2016) Moving citizens and deterring criminals: Innovation in public transport facilities. CAF Working Paper No. 2016/15

Carrillo PE, Malik AS, Yoo Y (2016) Driving restrictions that work? Quito's Pico y Placa Program. Can J Econ 49(4):1536-1568

Carruthers R, Dick M, Saurkar A (2005) Affordability of public transport in developing countries. World Bank, Washington, $\mathrm{DC}$

Carson RT (2000) Contingent valuation: a user's guide. Environ Sci Technol 34(8):1413-1418

Cerdá M, Morenoff J, Hansen B, Tessari Hicks KJ, Duque L, Restrepo A, Diez-Roux A (2012) Reducing violence by transforming neighborhoods: a natural experiment in Medellín, Colombia. Am J Epidemiol 175(10):1045-1053

Cervero R (2000) Informal transport in the developing world. United Nations Centre for Human Settlements (Habitat), Nairobi

Cervero R, Kang CD (2011) Bus rapid transit impacts on land uses and land values in Seoul, Korea. Transp Policy 18(1):102-116

Chen Y, Whalley A (2012) Green infrastructure: the effects of urban rail transit on air quality. Am Econ J Econ Policy 4(1):58-97

Cortes R, Lopera MA, Mitnik O, Yañez-Pagans P (2017) Impact evaluation in transport. Inter-American Development Bank, Washington, DC

Dávila J D, Daste D (2012) Medellin's aerial cable cars: Social inclusion and reduced emissions. UNEP-IPSRM Cities, Decoupling and Urban Infrastructure

Davis LW (2008) The effect of driving restrictions on air quality in Mexico City. J Polit Econ 116(1):38-81

Davis LW (2017) Saturday driving restrictions fail to improve air quality in Mexico City. Sci Rep 7(41652). http://www. thenewspaper.com/rlc/docs/2017/mexicoair.pdf

De la Torre A, Fajnzylber P, Nash J (2009) Low carbon, high growth: Latin American responses to climate change —an overview. World Bank, Washington, DC

Debrezion G, Pels E, Rietveld P (2007) The impact of railway stations on residential and commercial property value: a meta-analysis. J Real Estate Finance Econ 35(2):161-180

Delmelle EC, Casas I (2012) Evaluating the spatial equity of bus rapid transit-based accessibility patterns in a developing country: the case of Cali, Colombia. Transp Policy 20:36-46

Domencich T A, McFadden D (1975) Urban travel demand: A behavioral analysis. Charles River Associates Research Study. North-Holland, American Elsevier, Amsterdam

Dorna G, Ruffo H (2017) Evaluación de impacto del proyecto de mejora integral del Ferrocarril Gral. Roca, Ramal Plaza Constitución - La Plata. Unpublished

Duchéne C (2011) Gender and transport. International Transport Forum on Transport Society, Leipzig

Dutta U, Henze J (2015) Economic impacts of bus rapid transit in Southeast Michigan. Mineta Transportation Institute Publications, San Jose

Eboli L, Mazzulla G (2008) Willingness-to-pay of public transport users for improvement in service quality. Euro Transp 38:107-118

Eskeland GS, Feyzioglu T (1997) Rationing can backfire: the "Day Without a Car" in Mexico City. World Bank Econ Rev 11(3):383-408

Estupiñan N, Scorcia H, Navas C, Zegras C, Rodriguez D, Vergel-Tovar E, Gakenheimer R, Azán Otero S, Vasconcellos E (2018) Transporte y desarrollo en América Latina 1(1). Banco de Desarrollo de América Latina and CAF. http://sciot eca.caf.com/handle/123456789/1186. Accessed 1 Aug 2018

Fay M, Andres LA, Fox C, Narloch U, Slawson M (2017) Rethinking infrastructure in Latin America and the Caribbean: Spending better to achieve more. World Bank, Washington, DC 
Florian M, Gaudry M, Lardinois C (1988) A two-dimensional framework for the understanding of transportation planning models. Transp Res B 22B:411-419

Fox C (2018) Data science for transport: a self-study guide with computer exercises. Springer, Berlin

Franklin S (2017) Locaton, search costs and youth unemployment: experimental evidence from transport subsidies. Econ J. https://doi.org/10.1111/ecoj.12509

Gallego F, Montero JP, Salas C (2013) The effect of transport policies on car use: evidence from Latin American cities. J Public Econ 107:47-62

Gibbons S, Machin S (2004) Valuing rail access using transport innovations. Centre for Economic Performance. London, London School of Economics and Political Science

Goel D, Gupta S (2015) The effect of Metro expansions on air pollution in Delhi. Policy Research Working Paper 7448. World Bank, Washington, DC

Gonzalez-Navarro M, Turner M (2018) Subways and urban growth: Evidence from earth. Unpublished. https://www. brown.edu/Departments/Economics/Faculty/Matthew_Turner/papers/unpublished/GonzalezNavarro_Turne r_unp_2018.pdf. 21 Accessed Aug 2019

Goodship P (2015) The impact of an urban cable-car transport system on the spatial configuration of an informal settlement. In: Proceedings of the 10th international space syntax symposium

Green J, Sánchez S (2013) Air quality in Latin America: An overview. Clean Air Institute. http://thecleanairinstitute.org/ calidaddelaireamericalatina/cai-report-english.pdf. Accessed 1 Aug 2018

GTZ Sector Project Transport Policy Advisory Service (2007) Gender and urban transport: smart and affordable. Eschborn, Germany

Guthrie A, Fan Y (2016) Economic development impacts of bus rapid transit. Center for Transportation Studies, University of Minnesota. Retrieved from the University of Minnesota Digital Conservancy. https://conservancy.umn.edu/ handle/11299/178988. Accessed 31 July 2018

Harris C, Ullman E (1945) The nature of cities. Ann Am Acad Pol Soc Sci 242:7-17

Hatzopoulou M, Miller EJ (2010) Linking an activity-based travel demand model with traffic emission and dispersion models: transport's contribution to air pollution in Toronto. Transp Res Part D 15:315-325

Heinrichs D, Bernet JS (2014) Public transport and accessibility in informal settlements: aerial cable cars in Medellin, Colombia. Transp Res Proc 4:55-67

Holzer HJ, Quigley JM, Raphael S (2003) Public transit and the spatial distribution of minority employment: evidence from a natural experiment. J Policy Anal Manage 22(3):415-441

Hoyt H (1939) The structure and growth of residential neighborhoods in American cities. U.S. Federal Housing Administration, Washington, DC

ILO (2017) World employment and social outlook: trends for women 2017. International Labour Office, Geneva Infralatam (2018) Transport. http://en.infralatam.info/dataviews/227373/transport/. Accessed 15 Apr 2018

Inter-American Development Bank (IDB) (2013) Comparative case studies: IDB-supported urban transport projects. Office of Evaluation and Oversight Approach Paper. IDB, Washington, DC

Isard W (1956) Location and space-economy: a general theory relating to industrial location, market areas, land use, trade, and urban structure. Technology Press of Massachusetts Institute of Technology, Boston, and Wiley, New York

Kain JF (1968) Housing segregation, Negro employment, and metropolitan decentralization. Q J Econ 82(2):175-197

Kaltheier R (2002) Urban transport and poverty in developing countries: Analysis and options for transport policy and planning. Deutsche Gesellschaft für Technische Zusammenarbeit (GTZ) GmbH, Eschborn, Germany

Khattak A, Yim Y, Stalker Prokopy L (2003) Willingness to pay for travel information. Transp Res Part C 11:137-159

Knight RL, Trygg LL (1977) Evidence of land use impacts of rapid transit systems. Transportation 6:231-247

Lam TC, Small KA (2001) The value of time and reliability: measurement from a value pricing experiment. Transp Res Part E 37:213-251

Lau KH, Kam BH (2016) A Cellular Automata Model for Urban Land-Use Simulation. Environ Plan B: Plan Des 32(2):247-263

Lee LY, Cheah YK (2014) Willingness-to-pay for monorail services: case study in Penang, Malaysia. Pertanika J Soc Sci Hum 22(1):165-179

Li Z, Hong Y, Zhang Z (2017) An empirical analysis of on-demand ride sharing and traffic congestion. In: Proceedings of the 50th Hawaii international conference on system sciences

Loukaitou-Sideris A (2008) How safe is the ride? Evaluation of design and policy responses to women's fear of victimization and crime. University of California Transportation Center

Manheim ML (1979) Fundamentals of transportation systems analysis. MIT Press, Cambridge

Markose S, Alentorn A, Koesrindartoto D, Allen P, Blythe P, Grosso S (2007) Smart market for passenger road transport (SMPRT) congestion: an application of computational mechanism design. J Econ Dyn Control 31 (6):2001-2032

Martinez S, Sanchez R, Yañez-Pagans P (2018) Getting a lift: the impacts of aerial cable cars in La Paz, Bolivia. Inter-American Development Bank. Working Paper IDB-WP-00956

Martinez D, Mitnik O, Salgado E, Scholl L, Yañez-Pagans P (forthcoming) Connecting to Economic Opportunity: the Role of Public Transport in Promoting Women's Employment in Lima. Journal of Economics, Race, and Policy

Mclntosh JR, Newman P, Trubka R, Kenworthy J (2017) Framework for land value capture from investments in transit in car-dependent cities. J Transp Land Use 10(1):155-185

Medda F (2012) Land value capture finance for transport accessibility: a review. J Transp Geogr 25:154-161

Mendieta JC, Perdomo JA (2007) Especificación y estimación de un modelo de precios hedónico espacial para evaluar el impacto de Transmilenio sobre el valor de la propiedad en Bogotá. Documentos CEDE

Miller HJ, Shih-Lung S (2001) Geographic information systems for transportation. Oxford University Press, New York

Molin E, Timmermans H (2006) Traveler expectations and willingness-to-pay for Web-enabled public transport information services. Transp Res Part C Emerg Technol 14(2):57-67

Mullins JA, Washington E, Stokes RW (1990) Land use impacts of the Houston transitway system. Transp Res Rec 1237:29-38 
Munoz-Raskin R (2010) Walking accessibility to bus rapid transit: does it affect property values? The case of Bogotá, Colombia. Transp Policy 17(2):72-84

O'Callaghan E (2016) Transit concerns in Bogotá: Is bus rapid transit a victim of its own success? Sustainable Transportation Lab. University of Washington. https://faculty.washington.edu/dwhm/2016/02/18/transit-concerns-in-bogot a-is-bus-rapid-transit-a-victim-of-its-own-success/. Accessed 30 July 2018

Osmond J, Woodcock A (2015) Are our streets safe enough for female users? How everyday harassment affects mobility. In: Contemporary ergonomics and human factors 2015: proceedings of the international conference on ergonomics \& human factors. Taylor \& Francis, London

Oviedo-Dávila N M (2017) Does proximity to massive transport systems reduce the probability of being informally employed? Evidence from Bogotá. Department of Geography and Environment. London School of Economics and Political Science. Unpublished

Park RE, Burgess EW (1925) The growth of the city: an introduction to a research project. University of Chicago Press, Chicago

Patacchini E, Zenou Y (2005) Spatial mismatch, transport mode, and search decisions in England. J Urban Econ 58:62-90

Pazos E (2016) The importance of public transport in Latin America. Intelligent Transport (3 May). https://www.intelligen ttransport.com/transport-articles/19098/importance-public-transport-latin-america/. Accessed 21 Aug 2019

Perdomo JA (2011) A methodological proposal to estimate changes of residential property value: case study developed in Bogotá. Appl Econ Lett 18:1577-1581

Perez P, Martinez F, Ortuzar J (2003) Microeconomic formulation and estimation of a residential location choice model: implications for the value of time. J Reg Sci 43(4):771-789

Phillips DC (2014) Getting to work: experimental evidence on job search and transportation costs. Labour Econ 29:72-82

Rayle L, Shaheen S, Chan N, Dai D, Cervero R (2014) App-based, on-demand ride services: comparing taxi and ridesourcing trips and user characteristics in San Francisco. University of California Transportation Center Working Paper

Rodrigue JP, Comtois C, Slack B (2017) The geography of transport systems, 4th edn. Routledge, New York

Rodríguez DA, Mojica CH (2009) Capitalization of BRT network expansions effects into prices of non-expansion areas. Transp Res Part A Policy Pract 43(5):560-571

Rodriguez DA, Targa F (2004) Value of accessibility to Bogotá's bus rapid transit system. Transp Rev 24(5):587-610

Roldán JSV, Zapata JCA (2013) El sistema Metrocable Línea Ky su impacto en la calidad de vida de la población de la comuna uno en la ciudad de Medellin: Análisis de percepción entre los años 2004-2008. Revista Movimentos Sociais e Dinâmicas Espaciais 2(1):74-94

Sanchez TW (1999) The connection between public transit and employment: the case of Portland and Atlanta. J Am Plann Assoc 65:284-296

SanchezTW, Shen Q, Peng ZR (2004) Transit mobility, jobs access and low-income labour participation in us metropolitan areas. Urban Stud 41(7):1313-1331

Scholl L, Martinez D, Mitnik O, Oviedo D, Yañez-Pagans P (2018) A rapid road to employment?: The impacts of a bus rapid transit system in Lima. Inter-American Development Bank. Working Paper IDB-WP-00980

Senbil M, Kitamura R (2004) Willingness-to-pay for expressways. International conference on experiments in economic science: new approach to solving real world problems. Okayama and Tokyo. http://www.cc.kyoto-su.ac.jp/project/ orc/execo/EES2004/EES/EES_33(abst).pdf. Accessed 31 July 2018

Shiftan Y (2000) The advantage of activity-based modelling for air-quality purposes: theory vs practice and future needs. Innovation 13(1):95-110

Simicevic J, Milosavljevic N, Djoric V (2016) Gender differences in travel behaviour and willingness to adopt sustainable behaviour. Transp Plan Technol 39(5):527-537

Stackelberg HV (2011) Marktform und gleichgewicht (Market structure and equilibrium). Springer, Berlin

Stokenberga A (2014) Does bus rapid transit influence urban land development and property values: a review of the literature. Transp Rev 34(3):276-296

Suárez-Alemán A, Serebrisky T (2017) ¿Los teleféricos como alternativa de transporte urbano? Ahorros de tempos em el sistema de teleférico urbano más grande del mundo: La Paz - El Alto. Inter-American Development Bank, Washington, DC. https://blogs.iadb.org/ciudades-sostenibles/es/telefericos-alternativa-transporte-urbano/. Accessed 21 Aug 2019

The Economist (2017) Subways in the sky: why Latin America is seeing a cable-car boom. The Americas. https://www. economist.com/the-americas/2017/10/26/why-latin-america-is-seeing-a-cable-car-boom. Accessed 31 July 2018

Tobler W (1979) Cellular geography. Philosophy in geography. Springer, Berlin

TomTom (2017) Traffic index: measuring congestion worldwide. https:/www.tomtom.com/en_gb/trafficindex/

Troncoso R, de Grange L, Cifuentes LA (2012) Effects of environmental alerts and pre-emergencies on pollutant concentrations in Santiago, Chile. Atmos Environ 61:550-557

Tsivanidis N (2018) The aggregate and distributional effects of urban transit infrastructure: Evidence of Bogotá's TransMilenio. University of Chicago Booth School of Business Job Market Paper. Unpublished

Tyndall J (2017) Waiting for the R train: public transportation and employment. Urban Stud 54(2):520-537

UITP (2015) World metro figures, statistics brief. International Association of Public Transport

UN-Habitat (2012) The state of Latin American and Caribbean cities 2012: towards a new urban transition. United Nations Human Settlements Programme, Nairobi

United Nations (2011) World urbanization prospects: the 2011 revision. United Nations, Department of Economic and Social Affairs

Vasconcellos EA (2001) Urban transport, environment and equity. The case for developing countries. Earthscan, London Vasconcellos EA, Mendonça A (2016) CAF Observatorio de Movilidad Urbana: Informe 2015-2016. Banco de Desarrollo para América Latina. http://scioteca.caf.com/handle/123456789/981. Accessed 21 Aug 2019

Vassallo Magro JM (2015). Asociación Público Privada en América Latina. Aprendiendo de la experiencia. Corporación Andina de Fomento

Vuchic VR (2002) Bus semirapid transit mode development and evaluation. Journal of Public Transportation 5(2):71-95

Wardman M (2001) A review of British evidence on time and service quality valuations. Transp Res Part E 37:91-106 
Wardrop JG, Whitehead JI (1952) Road paper: some theoretical aspects of road traffic research. ICE Proc Inst Civil Eng 1(3):325-362

Waze (2016) Driver satisfaction index. https://inbox-static.waze.com/driverindex.pdf. Accessed 21 Aug 2019

Worku GB (2013) Demand for improved public transport services in the UAE: a contingent valuation study in Dubai. Int J Bus Manage 8(10):108-125

World Health Organization (WHO) (2017) Global ambient air pollution. http://maps.who.int/airpollution/. Accessed 21 Aug 2019

WRI Brazil Ross Center for Sustainable Cities (2018) Global BRT data. World Resources Institute BRTData Project. https:// brtdata.org/. Accessed 21 Aug 2019

Zhang W, Lawell CYCL, Umanskaya VI (2017) The effects of license plate-based driving restrictions on air quality: theory and empirical evidence. J Environ Econ Manage 82:181-220

\section{Publisher's Note}

Springer Nature remains neutral with regard to jurisdictional claims in published maps and institutional affiliations.

Submit your manuscript to a SpringerOpen ${ }^{\circ}$ journal and benefit from:

- Convenient online submission

- Rigorous peer review

- Open access: articles freely available online

- High visibility within the field

- Retaining the copyright to your article

Submit your next manuscript at $\gg$ springeropen.com 